\title{
Measurement of Contrails Using ADS-B Data
}

\author{
Ing. Martin Voráček \\ Department of Air Transport \\ CTU \\ Czech Republic \\ voracma1@fd.cvut.cz
}

\author{
Ing., Bc. Jakub Hospodka, Ph.D. \\ Department of Air Transport \\ CTU \\ Czech Republic \\ xhospodka@fd.cvut.cz
}

Abstract - Air transport contributes to climate changes not only by greenhouse gas production but also because of production of contrails. The effect of contrails is less scientifically understood compared to greenhouse gases according to IPCC [3].

In order to be able to research the effect of contrails on the atmosphere, it is necessary to identify their realistic frequency of occurrence and to define the relationship between their occurrence and other factors. The effort to identify and monitor contrails and their dependence on the type of air traffic is the objective of SGS project.

\section{Keywords-ADS-B, contrails}

\section{INTRODUCTION}

\section{A. System Description}

The measuring system consists of two subsystems. Optical recording - optical recording is carried out from a building of the Faculty of Transportations Sciences, Czech Technical University in Prague which is located in Děčín. This site has been chosen for its advantageous position in the proximity of several upper airspace ATS routes. Figure 1 - En-route Chart - Upper Airspace shows the system of routes in Prague FIR. passes through the region. OMELO waypoint is particularly significant for observations. It is a non-compulsory reporting point on L620 and Z21 routes. These routes are unidirectional at flight levels 245-660, which are levels where contrail formation can be expected. This waypoint is suitable for the research because it connect the aforementioned routes to other routes in Germany, which continue beyond that point with a different direction. As a result, an aircraft overflying the waypoint changes its heading by more than $15^{\circ}$ and the resulting contrail hence creates a very distinct curved pattern, Figure 2.

\section{OPTICAL SURVEILLANCE}

The curved shape is significant in that it possibly facilitates the identification of induced cloud, which can be formed from contrails in specific circumstances. Induced cloud covers a major part of the sky, which noticeably increases the negative impact of contrails on the radiation balance of the Earth. Induced cloud also probably leads to changes in condensation processes of the respective air mass. Although the exact impact is not known, it is estimated that premature condensation resulting from air transport may result in regional rain shadow. The cause of this phenomenon is the

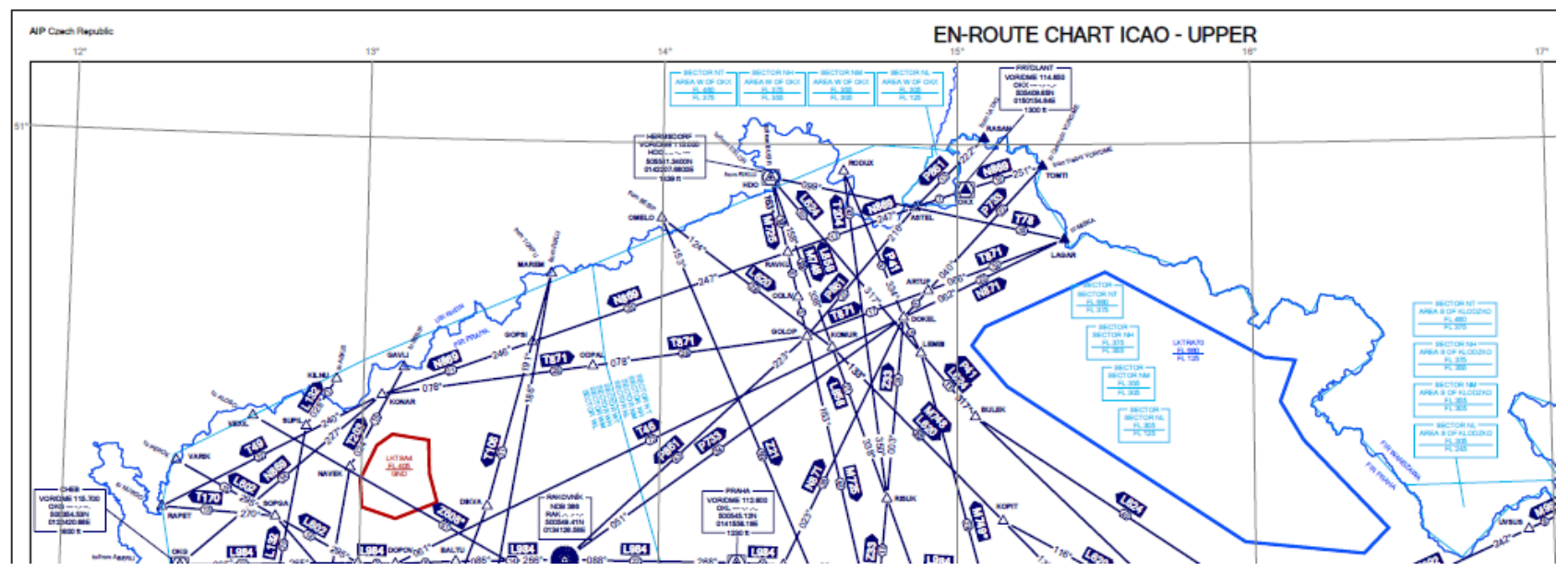

Figure 1 En-raoute chart (AIP ČR)

cloud that is formed prematurely compared to an aircraft-free situation, while the size of coagulation particles is insufficient to lead to further condensation. Moisture which gradually

Děčín lies in a region bordered by ATS routes from all directions and this is reflected in the amount of air traffic that 
evaporates without falling down to the Earth's surface is then absent in the water content of the original air mass. This shortage then results in less precipitation or even in its complete lack. A contrary effect has been observed in cirrus clouds above oceans in the area of so called Ship cloud. Cirrus cloud is characterized by its occurrence at high levels and the lack of precipitation. Nevertheless, as a result of anthropogenic effects, cirrus clouds can produce precipitation under certain circumstances, which again result in a negative impact on rainfall in other regions. Given the fact that this phenomenon has mostly been observed in areas with high maritime traffic, it leads to higher rainfall over the ocean and rain shadow over land where it negatively affects hydrology.

\section{ADS-B}

ADS-B is used for aircraft identification, in particular Radarcape ADS-B receiver by Planevision Systems GmbH. There are two devices in order to be able to use the second signal in case of loss of the first one. Both receivers are installed in Prague, one on the building of student dormitories in Strahov, the second one is on Citytower building in Pankrac. The location of the receivers does not enable signal reception in $360^{\circ}$ because their view is partially blocked by other buildings.

Figure 3 shows that both receivers located in Prague have sufficient coverage for aircraft surveillance in the region of Děčín. The distance between Děčín and Prague is

\section{3-11-2015 Tue 16:33:35}

Figure 2 Curve contrail captured 3/112015 cam 3

Included contrails should become the basis of further research of cirrus cloud. In contrast to linear clouds, it is possible to positively identify a given cirrus cloud as originating from an overflying aircraft because of its shape corresponding to the aircraft's track. It is impossible to determine this for linear clouds because their shape can also result from natural conditions such as a boundary between a warm and cold air mass in an occluded front.

Due to their technical limitations, cameras cannot be pointed directly into the sun to prevent damage to their lenses. It is therefore necessary to choose monitoring angles according to the season and the sun's elevation. Another technical problem which had to be solved is the icing of the lens. This was solved by the installation of remote camera cover heating which can be manually turned on when needed.

Ground-based records would not be sufficient for the identification of each contrail, hence it is necessary to assign each contrail to a specific aircraft. It must be done because of several reasons. approximately $100 \mathrm{~km}$ and the town is located to the north of Prague.

\section{Coverage Pattern $(\mathrm{km})$}

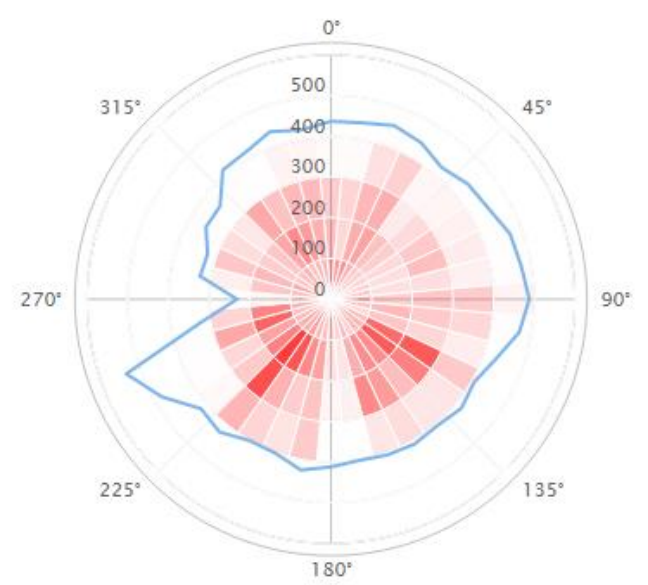

Figure 3 range pattern Strahov 


\section{Coverage Pattern (km)}

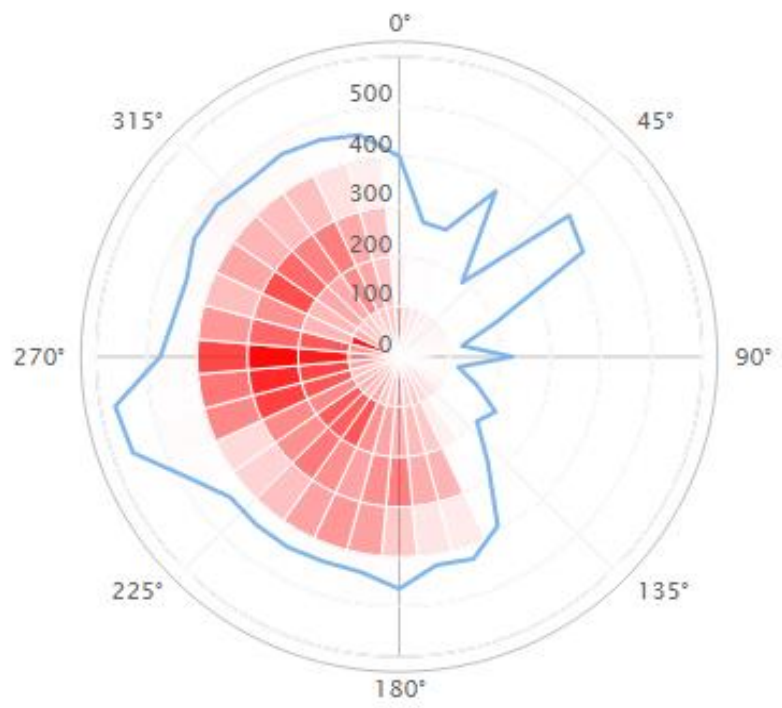

Figure 4 range pattern Pankrác

The blue area is covered with sufficient signal. The range is satisfactory for both receivers. The receiver in Pankrac had to be relocated on the building to prevent signal blocking.

As shown in Figures 3 and 4, the ADS-B system located in Prague covers a vast area and therefore captures a large number of messages. Table 1 shows the average number of messages of other messages (blue) and position messages (red) per hour.

\section{Messages / Hours}

$4 \mathrm{M}$

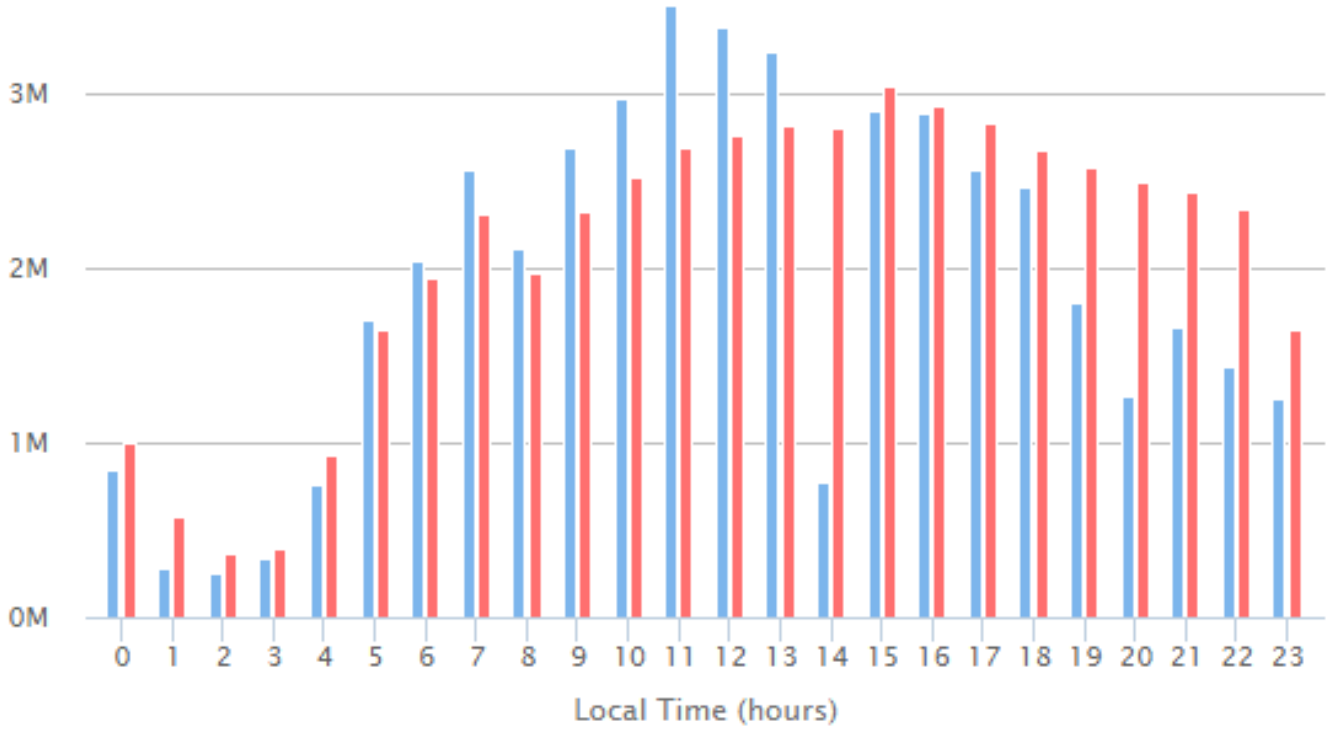

Figure 5 message/hour statistics
The above shown amount of messages represents data flow of more than $10 \mathrm{~Gb}$ per day. In order to simplify processing and to be able to store and back up the data, this amount must be reduced.

\section{DATA FILTERING}

A key element of data filtering is to determine which messages are to be recorded and which can be filtered out. Only records of aircraft operating in the region monitored by the cameras in Děcín are important for contrail research among all the recorded ADS-B messages.

Filtering is therefore based on the geographic position contained in the message, in particular in the region between N50.85 and N50.5833 and E14.3667 and E13.9833, which covers the whole area visually monitored from Děčín up to a distance of $20 \mathrm{~nm}$. Beyond that distance, it is not possible to observe contrails even with the highest resolution of the recording device. The filtering is hence performed based on the geographic position contained in the message. The determination of the aircraft's position is rather a complex mathematic operation because of its CPR (Compact Position Reporting) format coding. In order to reduce message size, it is necessary to determine if the CPR format messages contain an even or odd frame, each of them containing different information, either the latitude or the longitude. [4]

Furthermore, it is necessary to bear in mind that CPR decodes position within zones determined by the receiver. With respect to the number of zones, it is assured that an airborne aircraft will not be detected in an incorrect geographic position when within $360 \mathrm{~nm}$ from the transmitter. More precisely there maybe detected aircraft from another zone after each 180 NM but position which would be equivavalent to our determined position is another $180 \mathrm{NM}$, so in general the distance is $360 \mathrm{NM}$. Considering Figures 3 and 4, we may ascertain that there is no risk of incorrect position detection for our receivers.

Aircraft level, time of overflying the monitored region, call sign to determine aircraft type and the 
direction of flight is extracted from the data contained in ADS-B messages.

The direction of flight was not originally extracted from the messages but it has turned out to be crucial for identifying a particular aircraft when more aircraft overfly the area at the same time. The size of the aircraft is insufficient for this purpose. In contrast, the direction of flight is sufficient for distinguishing between two aircraft flying in the same area at the same time. The only situation when positive identification could not be achieved would be the case of two aircraft flying in the same area along the same route, i.e. in the same direction, and at the same time flying too high to be able to distinguish between them using their mutual vertical separation. This situation was encountered only once during the 90 observations performed. As a result, we consider the currently collected amount of data to be sufficient.

All ADS-B data and the majority of camera recordings are stored so that it is possible to verify the correctness of contrail formation statistics which is being developed.

\section{CONCLUSION}

With Paris agreement adopted, there very will increased pressure on countries to fulfil their obliges with respect to reducing impact on climate. Problematics of contrails seems to be one of most promising way to reduce impact of aviation on atmospehere. At current state is effort of DAT prepared to actively help in revelation of contrails impact on atmosphere. After real impact estimated there shall be next effort to find way how use these knowledge to reduce the impact of aviation.

\section{REFERENCES}

[1] Plos, V., Szabo, S.: The Usage of MEDA Factors for Risk Assessment of Processess in Aircraft Maintenance 2015 In: Selected Risks of Business Processes. Praha: ČVUT v Praze, Fakulta dopravní, Ústav bezpečnostních technologií a inženýrství, 2015, p. 55-61., ISBN 978-80-01-05831-2.

[2] Szabo, S., Koblen, I., Vajdová, I.: Aviation Technology Life Cycle Stages 2015 In: eXclusive e-JOURNAL. 2015, vol. 3, no. 3, ISSN 1339-4509. [3] IPCC, 2013: Climate Change 2013: The Physical Science Basis. Contribution of Working Group I to the Fifth Assessment Report of the Intergovernmental Panel on Climate Change [Stocker, T.F., D.Qin, G.-K. Plattner, M. Tignor, S.K. Allen, J. Boschung, A. Nauels, Y. Xia, V. Bex and P.M. Midgley (eds.)]. Cambridge University Press, Cambridge, United Kingdom and New York, NY, USA, 1535 pp, doi:10.1017/ CBO9781107415324.

[4] AIRCRAFT POSITION REPORT USING DGPS \& MODE- Subdivision B2.2. - 1995CommunicationsShttp://www.eurocontrol.int/eec/gallery/content/ public/document/eec/report/1995/002_Aircraft_Position_Report_using_DGPS _Mode-S.pdf

[5] Leták, F., Frynta, J., Endrizalová, E.: Optimization of Ground Navigation Aids of Regional Airports 2015 In: Aeronautika 15. Lublin: Lublin University of Technology, 2015, p. 210-214., ISBN 978-83-7947-149-2.

[6] Bugaj, M., Rostáš, J., Němec, V.: 3D Modeling from Airborne Laser Scanner 2015 In: GEO Spatial Visions. Žilina: EDIS, 2015, p. 15-16., ISBN 978-80-554-1113-2.

[7] Koblen, I., Talpaš, L., Jurčák, J.: Selected aspects of aviation equipment disposal issue 2012., Review of the Air Force Academy. Vol. 9, no. 2 (21) (2012), p. 102-108., ISSN 2069-4733.

[8] Kotianová, N., Stoláriková, K., Línek,M: Requirements Eurocontrol safety regulatory, Bezpečnost a doprava: Teorie a praxe $\mathrm{v}$ bezpečnosti a krizovém řízení $\mathrm{v}$ dopravě : 10 . konference $\mathrm{s}$ mezinárodní účastí : 14 . února 2014, Hradec Králové. - Pardubice : Inštitut Jana Pernera, 2014, P. 59-62., ISBN 978-80-86530-92-5. 